\title{
Aplicação de metodologias de inspeção em ponte de concreto armado
}

\author{
Application of inspection methods in reinforced concrete \\ bridges
}

\author{
Alisson Gadelha de Medeiros \\ Maria das Vitórias Vieira Almeida de Sá \\ José Neres da Silva Filho \\ Marcos Alyssandro Soares dos Anjos
}

\section{Resumo \\ $\mathbf{M}$}

anifestações patológicas atingem obras civis em ambientes agressivos distintos. Com isso, ações por inspeções técnicas e eventuais intervenções são necessárias através do uso de metodologias específicas, que minimizem subjetividades nesse processo e garantam soluções adequadas quanto à durabilidade. Este artigo aplica metodologias de inspeção em uma ponte situada no nordeste brasileiro. Para tanto, foram identificadas manifestações patológicas e escolhidos elementos a serem avaliados no cálculo de deterioração da metodologia GDE (grau de deterioração de estruturas) adaptada e análise técnica da norma DNIT. O grau de deterioração global da estrutura obtido pela metodologia GDE foi de 64,03, que qualifica em "nível de deterioração alto", e a nota técnica atribuída pela norma DNIT foi igual a 3 , sendo considerada uma estrutura como "potencialmente problemática". A experiência e qualificação técnica nessas avaliações são fatores imperativos. Entretanto, na metodologia GDE adaptada, a subjetividade da inspeção ficou reduzida com a existência de formulações matemáticas nas quais os elementos foram avaliados através das presentes manifestações patológicas por fatores de ponderação. Dessa forma, foi possível quantificar e classificar o estado de conservação da estrutura, indicar a necessidade de intervenção e obter comparação entre metodologias de inspeções em pontes, na garantia do refinamento de resultados e de reprodução em outras pesquisas.

${ }^{1}$ Alisson Gadelha de Medeiros 1 Universidade Federal Rural do SemiPau dos Ferros - RN - Brasil

${ }^{2}$ Maria das Vitórias Vieira Almeida de Sá 2Universidade Federal do Rio Grande do Norte Natal - RN - Brasil

${ }^{3}$ José Neres da Silva Filho ${ }^{3}$ Universidade Federal do Rio Grande do Norte Natal - RN - Brasil

${ }^{4,}$ Marcos Alyssandro Soares dos Anjos

${ }^{4}$ Instituto Federal de Educação, Ciência e Tecnologia da Paraíba ${ }^{5}$ Universidade Federal do Rio Grande do Norte João Pessoa - PB - Brasil

Palavras-chave: Inspeções visuais. Manisfestações patológicas. Grau de deterioração; Durabilidade.

\section{Abstract}

Pathological manifestations affect buildings in different aggressive environments. Thus, technical inspectionactions and occasional interventions are necessary, usingspecific methodologies that canminimise subjectivity in this process and guarantee adequate solutions regarding durability. This research study applies inspection methodologies to a bridge located in northeastern Brazil. The researchers identifiedpathological manifestations and elements to be evaluatedthroughthecalculation of deterioration with an adapted version of the GDE method (assessment of the degree of structuraldeterioration), and alsothrough a technical analysis of the DNIT standard. A "high" deterioration degree of 64.03 was obtained, as well as a technical grade of 3, characterising the structure as "potentially problematic". Experience and technical qualification arecrucialin these evaluations; however, the adapted GDE methodology has specificities thatreducesubjectivity, enhancing the inspection process andsetting the deadlines for eventual repairs. Hence, it was possible to quantify and classify the state of conservation of the structure, indicate the need for intervention and obtain comparisons between bridge inspectionmethods, ensuring the refinement of results and reproduction in other studies.

Recebido em 11/07/19 Aceito em 15/11/19
Keywords: Visual inspections. Pathological manifestations. Degree of deterioration. Durability. 


\section{Introdução}

O Brasil por ser um país de dimensões continentais, com diferentes perfis de relevo e rico em recursos hídricos, é dotado de uma extensa e preponderante malha rodoviária, representando $65 \%$ da matriz de transporte do país, segundo o Plano Nacional de Logística de Transporte (PLANO..., 2016). De acordo com o Sistema Nacional de Viação (SNV) do Departamento Nacional de Infraestrutura de Transportes (DEPARTAMENTO..., 2017a), o Brasil totaliza atualmente $65.512,2 \mathrm{~km}$ de rodovias federais pavimentadas e 11.001,5 km não pavimentadas. O Relatório Gerencial (Atlas de Manutenção Rodoviária) apresentado pelo (DEPARTAMENTO..., 2017b) indica a existência de 8.037 obras. As pontes e viadutos em um total de 7.191 representam 90\% das OAEs (obras de arte especiais). Ainda de acordo com o Relatório Gerencial, do total das obras, 97,52\% foram construídas em concreto armado e protendido (Figura 1).

Em complemento, observa-se que a maioria dessas pontes brasileiras foi executada em concreto armado e tem idade superior a 30 anos com escassas informações sobre seus materiais empregados e suas características mecânicas. Dessa forma, é oportuno mencionar que existe um costume bastante habitual de considerar que a vida útil das pontes seja extraordinariamente longa, talvez até infinita. Isso se deve, em parte, à impressão que, de modo geral, é transmitida por esse tipo de obra, sempre associada à robustez e solidez.

A realidade mostra, porém, que uma ponte, como qualquer outra edificação, também se deteriora com o passar do tempo e necessita de cuidados para não se debilitar e tornar-se vulnerável às ações de agentes, sejam eles endógenos ou exógenos, que ponham em risco as suas condições de estabilidade e funcionalidade. Nesse sentido, aplicações de metodologias de inspeção para pontes são pertinentes haja vista que, segundo Alsharqawi, Zayed e Abu Dabous (2018), a deterioração dessas estruturas é um problema bastante complexo para os departamentos de infraestrutura estadual e federal.

A metodologia grau de deterioração das estruturas (GDE) inicialmente desenvolvida por Klein et al. (1991) e posteriormente adaptada por Castro (1994), baseia-se na análise de dados coletados em inspeções realizadas em campo, que subsidiam na quantificação dos danos referentes às manifestações patológicas presentes, através de formulações para efetuar um valor deletério global.

De acordo Rosa et al. (2014), esse método permite a minimização da subjetividade da avaliação das estruturas, pois são aplicados fatores de ponderação nos danos identificados, que possui base na quantificação do grau de deterioração de estruturas de concreto.

A partir de sua publicação original, essa metodologia sofreu novas adaptações, sobretudo para avaliação de OAEs, sendo atualmente uma ferramenta bastante difundida no âmbito do estudo da durabilidade no Brasil (CAMPOS NETO et al., 2018).

Essas remodelagens foram implementadas nas pesquisas de Lopes (1998), Boldo (2002), Fonseca (2007), sendo uma das últimas adaptações desta metodologia a proposta por Euqueres (2011), a qual se adaptam aplicações em OAEs a partir da inserção de novos elementos (aparelhos de apoio, guarda-rodas, pista de rolagem, cortinas, etc.), bem como na estruturação dos fatores de relevância e alterações em alguns fatores de ponderação e nos prazos das ações a serem adotadas.

Figura 1 - Tipo de OEA e material empregado (Relatórios Gerenciais DNIT (DEPARTAMENTO..., 2017b)
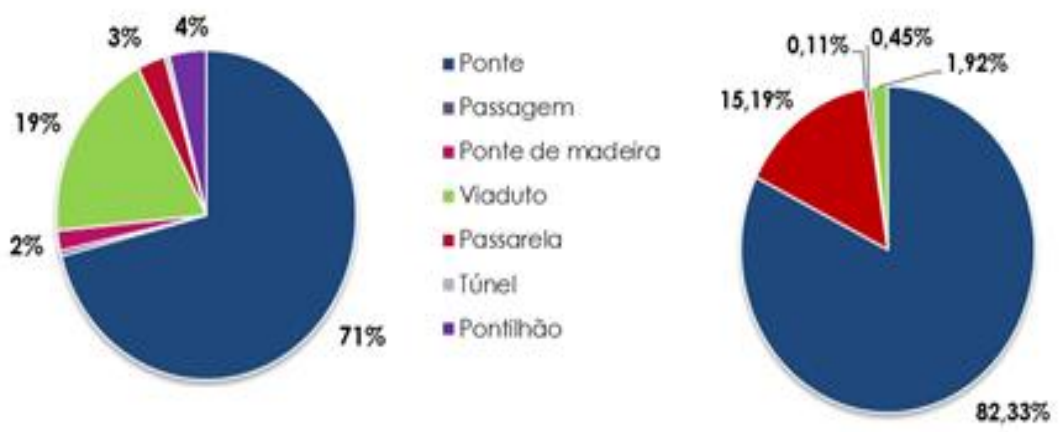

- Concreto Armado

- Concreto Protendido

- Metálico

- Madeira

- Mista (metálico e

concretol

688 Medeiros, A. G. de; Sá, M. das V. V. A. de; Silva Filho, J. N. da; Anjos, M. A. S. dos 
Na metodologia GDE, a quantificação dos danos tem por base distintos graus de deterioração, dentre os quais existem fatores de relevância estrutural $\left(F_{r}\right)$ das famílias dos elementos avaliados que variam de 1 a 5 , condicionado ao tipo de aplicação e considerando a preponderância na composição da estrutura avaliada e devida intensidade aplicada pelo fator de intensidade $\left(F_{i}\right)$ da manifestação patológica.

A avaliação pode ser realizada por meio de um programa de inspeções periódicas através do uso do roteiro de inspeção da metodologia. Esse procedimento é descrito no fluxograma apresentado por Castro (1994), também abordado nas demais reformulações. A Figura 2 ilustra o fluxograma da metodologia de cálculo do GDE.

A norma DNIT 010 (DEPARTAMENTO..., 2004) possui instruções direcionadas para avaliação de elementos em pontes com função estrutural, de acordo com o sistema de gerência de OAEs (SGO v3). Sua avaliação consiste em notas atribuídas aos elementos inspecionados (FONSECA, 2007).

De acordo com Rosa et al. (2014), durante as inspeções realizadas são coletadas informações sobre os danos e insuficiências estruturais instalados nos diferentes elementos analisados. Essas informações devem ser registradas em fichas de inspeção rotineira padronizadas. Nessa ficha, pode-se verificar que para cada elemento catalogado na OAE há um campo destinado para a atribuição de nota denominada de nota técnica (NT), a qual avalia as condições de cada elemento.

A NT possui pontuação máxima igual a 5, de acordo com o grau de deterioração. Ressalta-se que, quanto menor for a nota, mais próximo de 1 , mais graves são os problemas de degradações encontrados no elemento estrutural. Aos elementos não estruturais podem ser atribuídas apenas notas de dois a cinco. A estrutura como um todo também recebe uma NT, que refletirá sua condição como um conjunto. A nota da ponte corresponderá ao menor valor de avaliação entre os elementos inspecionados.

Figura 2 - Fluxograma da metodologia GDE

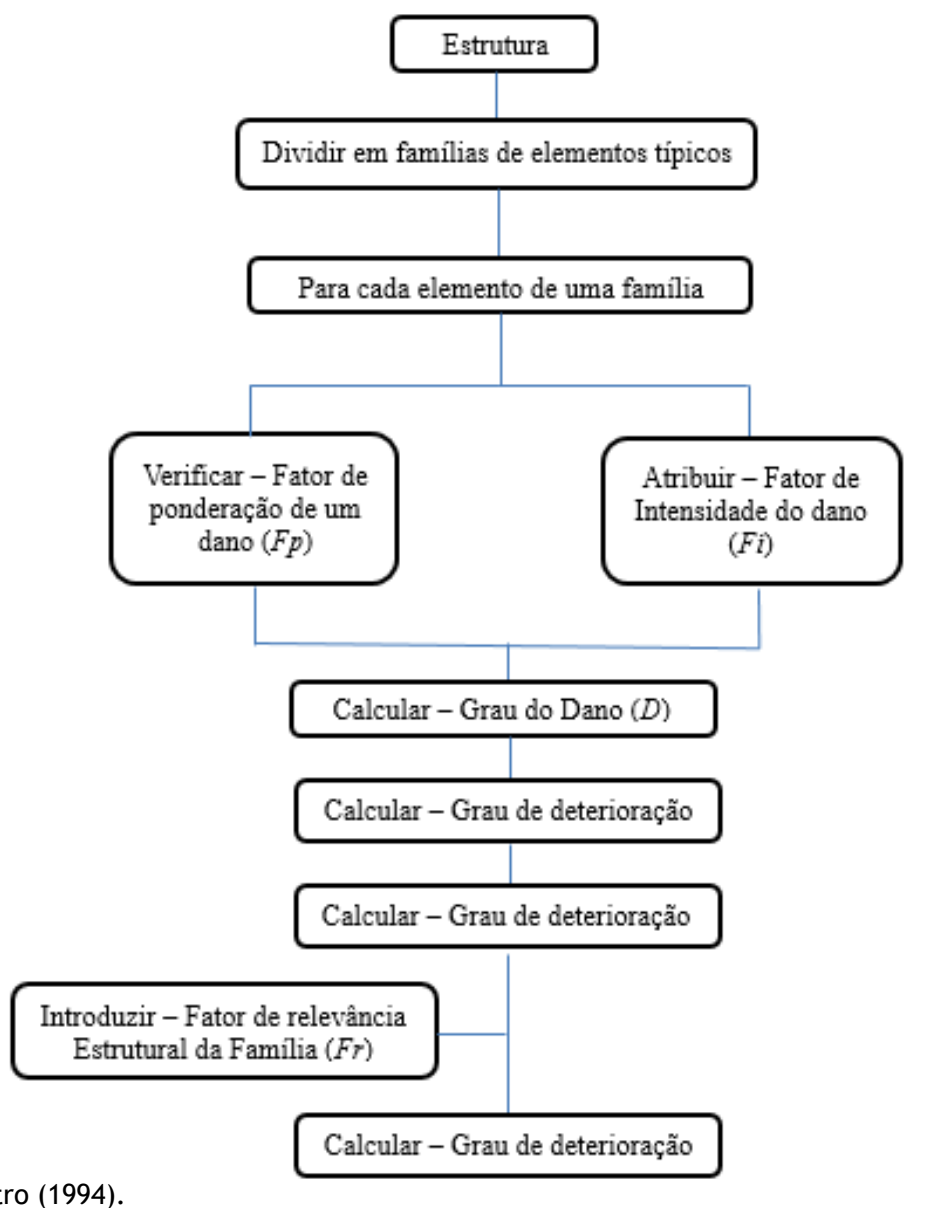

Fonte: adaptado de Castro (1994). 
Caso os procedimentos de reabilitação e recuperação forem negligenciados, os danos dessa magnitude podem fazer a estrutura atingir os estados limites de serviço (ELS) ou até mesmo, em uma situação mais crítica, a estrutura colapsar atingindo os estados limites últimos (ELU), ambos preconizados pela NBR 6118 (ABNT, 2014). Em relação aos danos, a norma DNIT 010 (DEPARTAMENTO..., 2004) regulamenta que eles devem ser amplamente fotografados e, eventualmente, representados em croquis.

Gonçalves (2011) aplicou a metodologia GDE no cálculo do grau de risco de marquises de concreto armado através das reformulações de Fonseca (2007), com algumas adaptações. As marquises inspecionadas indicaram ausência ou insuficiência da armadura negativa, fato proveniente de um erro na fase de construção, ou do incorreto posicionamento dessas armaduras. Com isso, a partir dos resultados do GDE, verificou-se a necessidade de intervenções imediatas para minimização de riscos.

Mendonça et al. (2014) avaliaram a durabilidade da estrutura de concreto armado de um estádio de futebol através de vistorias in loco que possibilitaram identificar o estado de deterioração resultante das diversas manifestações patológicas presentes. A aplicação da metodologia GDE, pela reformulação de Fonseca (2007), resultou no dano global de 148,53, que indicou estado crítico da obra avaliada havendo necessidade de uma inspeção emergencial.

Pereira (2014) realizou um estudo das condições gerais de conservação de reservatórios de um sistema de abastecimento aplicando a metodologia GDE reformulada por Fonseca (2007), bem como através da realização de ensaios não destrutivos in loco. Com isto, foi possível elaborar um plano de prioridade de intervenções dos reservatórios de concreto armado em estudo, de acordo com o grau de deterioração calculado.

Giovannetti e Pinto (2014) avaliaram os danos presentes em uma ponte por duas metodologias distintas: norma DNIT 010 (DEPARTAMENTO..., 2004)e a COST 345 utilizada na Eslovênia. Na aplicação da norma DNIT 010 (DEPARTAMENTO..., 2004) foram avaliadas longarinas, laje, drenagem de margem do rio. Foram atribuídas notas técnicas (NTs) para cada elemento avaliado, que ficaram numa margem de 3 a 5 , obtendo nota final igual a 3. Por fim, norma DNIT 010 (DEPARTAMENTO..., 2004) ajustou-se melhor às inspeções, porém a qualificação e experiência do inspetor evidenciaram-se como fundamentais para o sucesso da avaliação.

\section{Método}

As metodologias foram aplicadas em uma ponte de concreto armado com mais de 40 anos de construção, a ponte sobre o Rio do Carmo, localizada no km 36 da BR-110 próximo à cidade Mossoró, RN (Figura 3). De acordo com a NBR 6118 (ABNT, 2014), a ponte está situada em região de forte agressividade ambiental (Classe III), sendo solicitada por cargas permanentes e móveis.

A superestrutura da ponte é constituída por uma viga contínua de altura variável em forma de uma parábola de segundo grau e seção transversal de 12 metros de largura incluindo as lajes dos balanços laterais. A ponte possui quatro vãos internos de 20 metros e dois balanços de 5 metros, além de guarda-rodas, duas cortinas de extremidade e transversinas de apoio, totalizando 90 metros de extensão. A estrutura é de concreto armado produzido com alta taxa de agregado de seixo rolado de grande dimensão. Quanto à mesosestrutura, ela é formada pelos aparelhos de apoio do tipo neoprene, vigas de contraventamento e pilares com inércias variáveis. A infraestrutura é composta por uma fundação profunda do tipo tubulão contendo armaduras complementares na transição meso e infraestrutura.

Figura 3 - Ponte sobre o Rio do Carmo

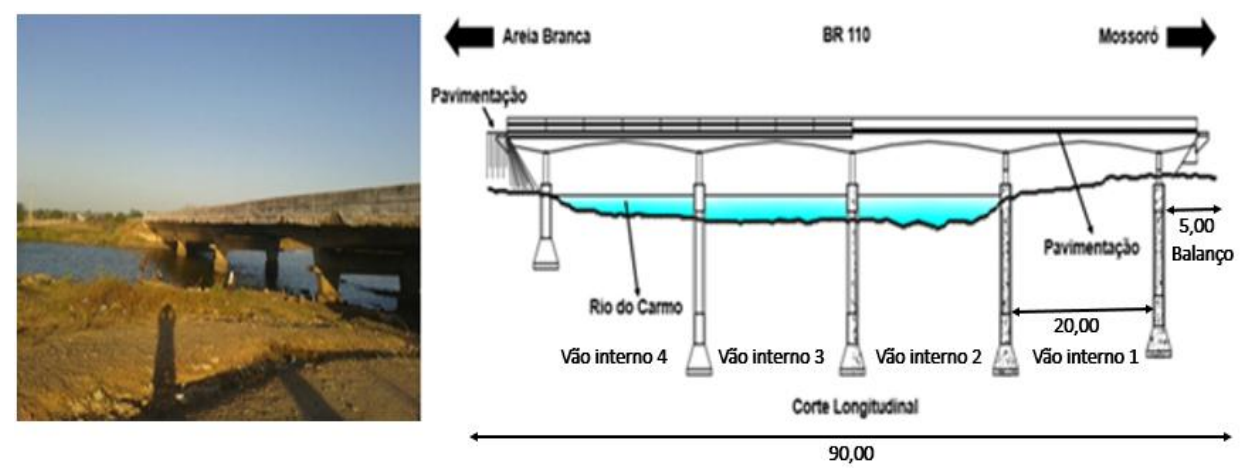

690 Medeiros, A. G. de; Sá, M. das V. V. A. de; Silva Filho, J. N. da; Anjos, M. A. S. dos 
As inspeções na OAE possibilitaram a identificação visual das manifestações patológicas presentes e a escolha dos elementos da obra que compuseram o cálculo GDE, bem como a aplicação da norma DNIT 010 (DEPARTAMENTO..., 2004).

Realizada a composição do cálculo do GDE (adaptada para OAE), incorporaram-se alguns elementos de importância estrutural que também fazem parte da análise técnica da norma DNIT 010 (DEPARTAMENTO..., 2004) (Quadro 1), a fim de permitir uma avaliação comparativa do estado de deterioração entre elementos avaliados nas duas metodologias (Figura 4).

\section{Quadro 1- Elementos que incorporaram o cálculo do grau de deterioração da estrutura (GDE)}

\begin{tabular}{|c|c|}
\hline Divisão estrutural & Elementos \\
\hline Superestrutura & Lajes (balanço da laje superior, de transição e vãos internos), cortinas \\
\hline Mesoestrutura & Aparelhos de apoio, vigas de contraventamento, pilares \\
\hline Infraestrutura & Blocos de coroamento \\
\hline Outros elementos & Vigas de fachada, guarda-rodas, juntas de dilatação, pista de rolagem \\
\hline
\end{tabular}

Figura 4 - Cortes da seção transversal

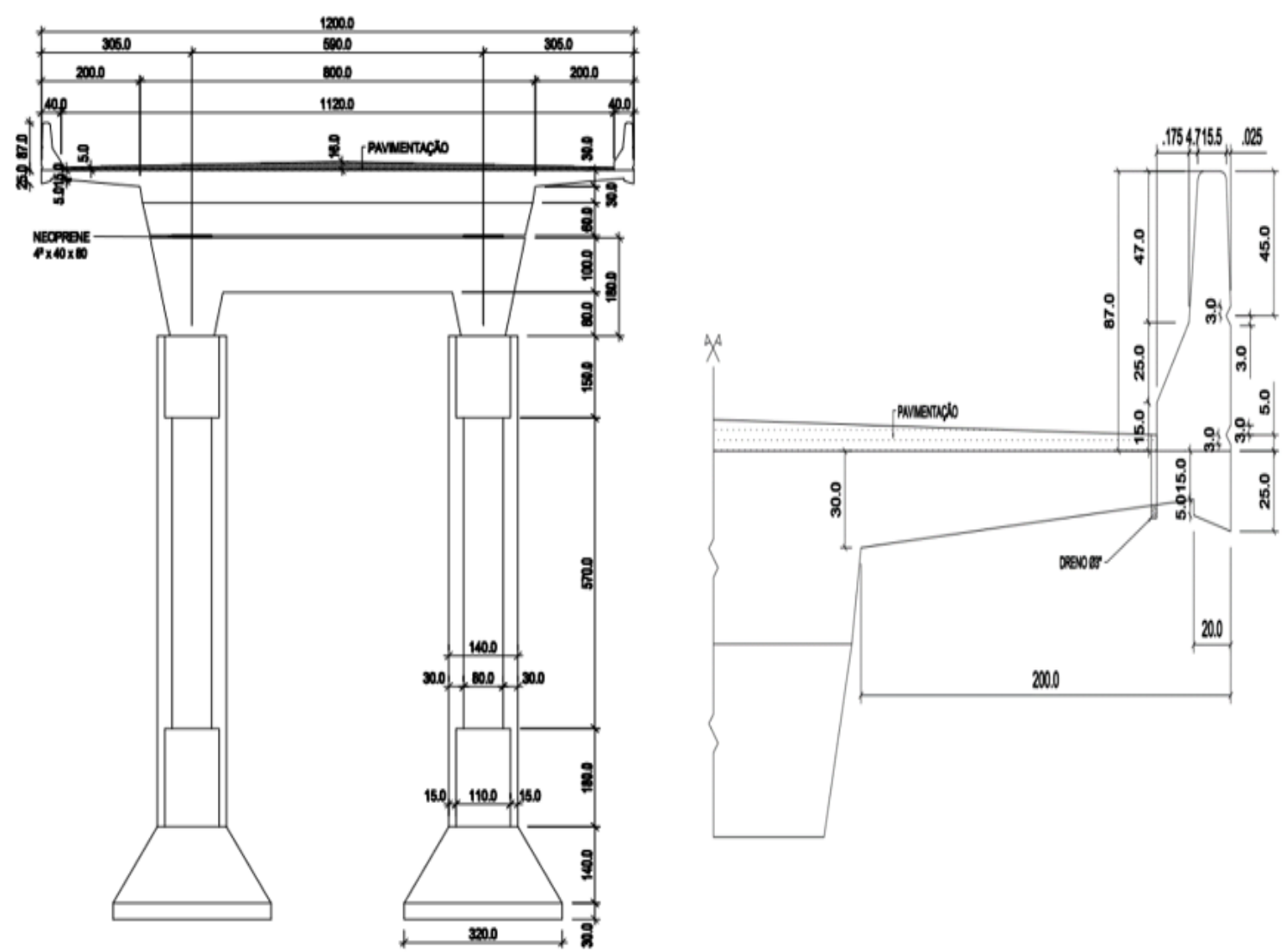

Todos os elementos foram classificados em famílias como sugere a metodologia GDE original e em elementos estruturais listados na norma DNIT 010 (DEPARTAMENTO..., 2004). Com isso, foram identificados os danos presentes, bem como atribuídos os devido fatores de ponderação, segundo o roteiro de inspeção da metodologia reformulada por Fonseca (2007) com as Equações 1 até 5 e as adaptações para pontes propostas em Euqueres (2011).

$D=0,8 F_{p} F_{i}$; para

Eq. 1

$D=\left(12 F_{i}-28\right) F_{p}$; para $F_{i}>2$

Eq. 2

$G_{d e}=D_{m a ́ x}\left[1+\frac{\sum_{i=1}^{m} D(i)-D_{m a ́ x}}{\sum_{i=1}^{m} D(i)}\right]$

Eq. 3 
$G_{d f}=G_{d e m a ́ x}\left[\sqrt{1+\frac{\sum_{i=1}^{m} G_{d e}(i)-G_{d e m} \text { áx }}{\sum_{i=1}^{m} G_{d e}(i)}}\right]$

$G_{d}=\frac{\sum_{i=1}^{m} F_{r}(i) G_{d f}(i)}{\sum_{i=1}^{m} F_{r}(i)}$

Onde:

D: dano;

$\mathrm{D}_{\text {máx }}$ : máximo dano;

$\mathrm{F}_{\mathrm{i}}$ : fator de intensidade;

$\mathrm{F}_{\mathrm{p}}$ : fator de ponderação;

$\mathrm{G}_{\mathrm{de}}$ : grau de deterioração de um elemento;

$\mathrm{G}_{\mathrm{demax}}$ : máximo grau de deterioração dos elementos;

$\mathrm{G}_{\mathrm{df}}$ : grau de deterioração da família;

$\mathrm{F}_{\mathrm{r}}$ : fator de relevância estrutural da família; e

$\mathrm{G}_{\mathrm{d}}$ : grau de deterioração da estrutura.

Para o cálculo da metodologia GDE adaptada para OAE, utilizaram-se duas variações na composição das famílias e na aplicação do roteiro de cálculo, com o objetivo de obter parâmetros de comparação e refinamento do grau deletério da estrutura em análise. Na primeira composição, as famílias foram agrupadas de acordo com o mesmo fator de relevância (famílias FR) com os seus valores modificados na adaptação por Euqueres (2011) e o cálculo da deterioração conforme formulação de Fonseca (2007). Quanto à segunda composição, cada elemento foi analisado individualmente e o agrupamento de seus similares correspondeu a uma família, por exemplo: "família das lajes", "família dos pilares", "família dos aparelhos de apoio" e outras.

Com relação ao procedimento de cálculo, assim como na primeira composição, utilizou-se a metodologia proposta por Fonseca (2007). Excetuando os fatores de intensidade para ambas, os outros fatores foram modificados e até mesmo acrescentados em uma nova proposta (Quadro 2), com base em manifestações patológicas em pontes encontradas através de estudos de caso já pesquisados (COSTA; APPLETON, 2002; ARAÚJO; PANOSSIAN, 2010; ANN et al., 2010; ABOUHAMAD et al., 2017; ZHOU et al., 2018). Essas alterações também foram embasadas quanto à gravidade da patologia, à causa e incidência das manifestações e à forma.

Ademais, tendo em vista a gravidade dos danos e as técnicas construtivas dos reparos, os prazos das ações de recuperação foram alterados, baseados na diferença existente entre construção civil de edifícios e OAEs, visto que esses prazos na aplicação da metodologia GDE adaptada para OAE podem ser influenciados na diferença de nível de deterioração caso sejam postergados por maiores intervalos de tempo.

\section{Quadro 2 - Exemplos de reformulações dos Fis adaptadas para pontes}

\begin{tabular}{|c|c|}
\hline Tipos de danos & Fator de intensidade do dano \\
\hline \multirow{3}{*}{$\begin{array}{l}\text { Cobrimento } \\
\text { insuficiente }\end{array}$} & $\begin{array}{l}1^{(*)}-\text { menores que os previstos em norma, permitindo de certa forma a localização } \\
\text { de alguma barra da armadura; }\end{array}$ \\
\hline & $\begin{array}{l}2 \text { - menor que o previsto em norma, permitindo a localização visual da armadura ou } \\
\text { armadura exposta em pequenas extensões; }\end{array}$ \\
\hline & 3 -insuficiente, com armaduras expostas em extensões significativas. \\
\hline \multirow{3}{*}{$\begin{array}{l}\text { Corrosão das } \\
\text { armaduras }\end{array}$} & $\begin{array}{l}2^{(*)}-\text { manifestações leves, pequenas manchas e/ou, de certa forma, permitindo a } \\
\text { localização de alguma barra da armadura; }\end{array}$ \\
\hline & $\begin{array}{l}3^{(*)}-\text { grandes manchas e/ou fissuras de corrosão, com exposição de armaduras em } \\
\text { pequenas ou médias áreas por desplacamentos; }\end{array}$ \\
\hline & $\begin{array}{l}4^{(*)}-\text { corrosão acentuada na armadura principal, com perda relevante de seção, em } \\
\text { regiões iguais ou superiores a } 50 \% \text { da área do elemento. }\end{array}$ \\
\hline
\end{tabular}

Fonte: adaptado de Euqueres (2011).

Nota: ${ }^{(*)}$ fatores de intensidade reformulados. 
$\mathrm{Na}$ Tabela 1 são indicadas as alterações propostas quanto aos prazos das ações a serem adotadas, de acordo com o nível de deterioração global $G_{d}$, com aumentos de até $50 \%$ dos prazos estabelecidos para pontes em Euqueres (2011). Isso pode ser justificado levando em consideração que pequenos prazos remetem a pontes com necessidades emergenciais em sua reabilitação.

Com isso, os aumentos dos prazos tiveram objetivo de permitir maior tempo hábil para realização de inspeções mais específicas, baseados na menor possibilidade de aumento de nível de deterioração da estrutura analisada.

Ressalta-se que, mesmo nas OAEs em estado estável e condicionado à agressividade ambiental da região situada, manutenções de caráter preventivo são necessárias. Em virtude dessas obras sofrerem os primeiros danos em mais ou menos uma década, foi indicado prazo de 5 anos para níveis de baixa de deterioração. Nesse contexto, em uma ponte de quase duas décadas de exposição urbana, Ann et al. (2010) analisaram os danos da carbonatação, sob condições atmosféricas anuais de 355 ppm de concentração de $\mathrm{CO}_{2}$ que afetam a durabilidade da estrutura.

Quanto às formas das composições de famílias, essas foram utilizadas na busca de justificar de buscar o refinamento da metodologia, de acordo com as maiores quantidades de famílias na incorporação do cálculo.

A Tabela 2 ilustra as composições das famílias que foram analisadas no cálculo do GDE adaptada para OAE, para avaliar o estado de degradação da ponte sobre o Rio do Carmo. As "famílias FR" formaram cinco agrupamentos e, para as "famílias divididas", formaram 10 agrupamentos de famílias.

Nas alterações dos prazos das ações a serem adotadas, levou-se em consideração a importância dos elementos estruturais e a estabilidade global da obra, pois na busca de se quantificar o dano global real da estrutura na utilização da metodologia GDE adaptada para OAE, tanto para as famílias denominadas de "FR" quanto as "divididas" foram submetidas para as duas variações supracitadas.

Tabela 1 - Prazos reformulados para ponte das ações a serem adotadas segundo a avalição global da estrutura

\begin{tabular}{c|c|l}
\hline Nível de deterioração & $\boldsymbol{G}_{\boldsymbol{d}}$ & \multicolumn{1}{c}{ Ações a serem adotadas } \\
\hline Baixo & $\leq 15$ & Estado estável. Manutenção preventiva (cada 5 anos) $^{(*)}$. \\
\hline Médio & $16-50$ & $\begin{array}{l}\text { Definir prazo/natureza para nova inspeção. Planejar intervenção } \\
\text { em médio prazo (máximo 3 anos) }\end{array}$ \\
\hline Alto & $51-80$ & $\begin{array}{l}\text { Definir prazo/natureza para inspeção especializada detalhada. } \\
\text { Planejar intervenção em curto prazo (máximo 2 anos) }\end{array}$ \\
\hline Sofrível & $81-100$ & $\begin{array}{l}\text { Definir prazo/natureza para inspeção especializada detalhada. } \\
\text { Planejar intervenção em curto prazo (máximo 1,5 anos) }\end{array}$ \\
\hline Crítico & $\geq 101$ & Inspeção especial emergencial. Planejar intervenção imediata. \\
\hline
\end{tabular}

Fonte: adaptado de Euqueres (2011).

Nota: ${ }^{(*)}$ prazos alterados.

Tabela 2 - Composição das famílias para o cálculo do GDE

\begin{tabular}{|c|c|c|c|c|}
\hline \multicolumn{5}{|c|}{ Famílias FR / Fatores de relevância } \\
\hline FR1 / Fr=1 & FR2 / Fr=2 & FR3 / Fr=3 & FR4 / Fr=4 & FR5 / Fr=5 \\
\hline $\begin{array}{l}\text { 1. Guarda- } \\
\text { rodas. }\end{array}$ & $\begin{array}{l}\text { 1. Pista de rolagem; } \\
\text { 2. Vigas de } \\
\text { fachada. }\end{array}$ & $\begin{array}{l}\text { 1. Juntas de } \\
\text { dilatação; } \\
\text { 2. Cortinas. }\end{array}$ & $\begin{array}{l}\text { 1. Lajes; } \\
\text { 2. Aparelhos de apoio; } \\
\text { 3. Blocos de coroamento. }\end{array}$ & $\begin{array}{l}\text { 1. Vigas de } \\
\text { contraventamento; } \\
\text { 2. Pilares. }\end{array}$ \\
\hline \multicolumn{5}{|c|}{ Famílias divididas (agrupamento dos elementos) } \\
\hline \multicolumn{3}{|c|}{ Blocos de coroamento } & \multicolumn{2}{|l|}{ Pilares } \\
\hline \multicolumn{3}{|c|}{ Vigas de contraventamento } & \multicolumn{2}{|c|}{ Aparelhos de apoio } \\
\hline \multicolumn{3}{|c|}{$\begin{array}{c}\text { Lajes (balanço da laje superior, de transição e } \\
\text { vãos internos) }\end{array}$} & \multicolumn{2}{|c|}{ Vigas de fachada } \\
\hline \multicolumn{3}{|c|}{ Guarda-rodas } & \multicolumn{2}{|c|}{ Juntas de dilatação } \\
\hline \multicolumn{3}{|c|}{ Cortinas } & \multicolumn{2}{|c|}{ Pista de rolagem } \\
\hline
\end{tabular}




\section{Resultados e discussão}

\section{Manifestações patológicas}

As manifestações patológicas da ponte foram observadas em todas as partes da superestrutura, mesoestrutura, infraestrutura. Das inspeções visuais realizadas na localidade da obra, foram verificadas, de forma geral, as seguintes manifestações patológicas: trincas e fissuras, erosão (abrasão) e acúmulo de materiais flutuantes na transição do pilar-tubulão, manchas de umidade, eflorescência, desplacamento, desagregação do concreto, "ninhos" de concretagem, áreas com cobrimento insuficiente, corrosão de armaduras, armaduras expostas, corroídas, rompidas, patologias por causas físicas na pavimentação e juntas de dilatação. Essas manifestações patológicas estão ilustradas nas Figuras 5 a 7.

Figura 5 - Manifestações patológicas encontradas nos balanços da face interna da laje superior; (1) manchas de umidade e instalação de drenagem disfuncional, (2) desagregação do concreto, (3) eflorescências e manchas de corrosão

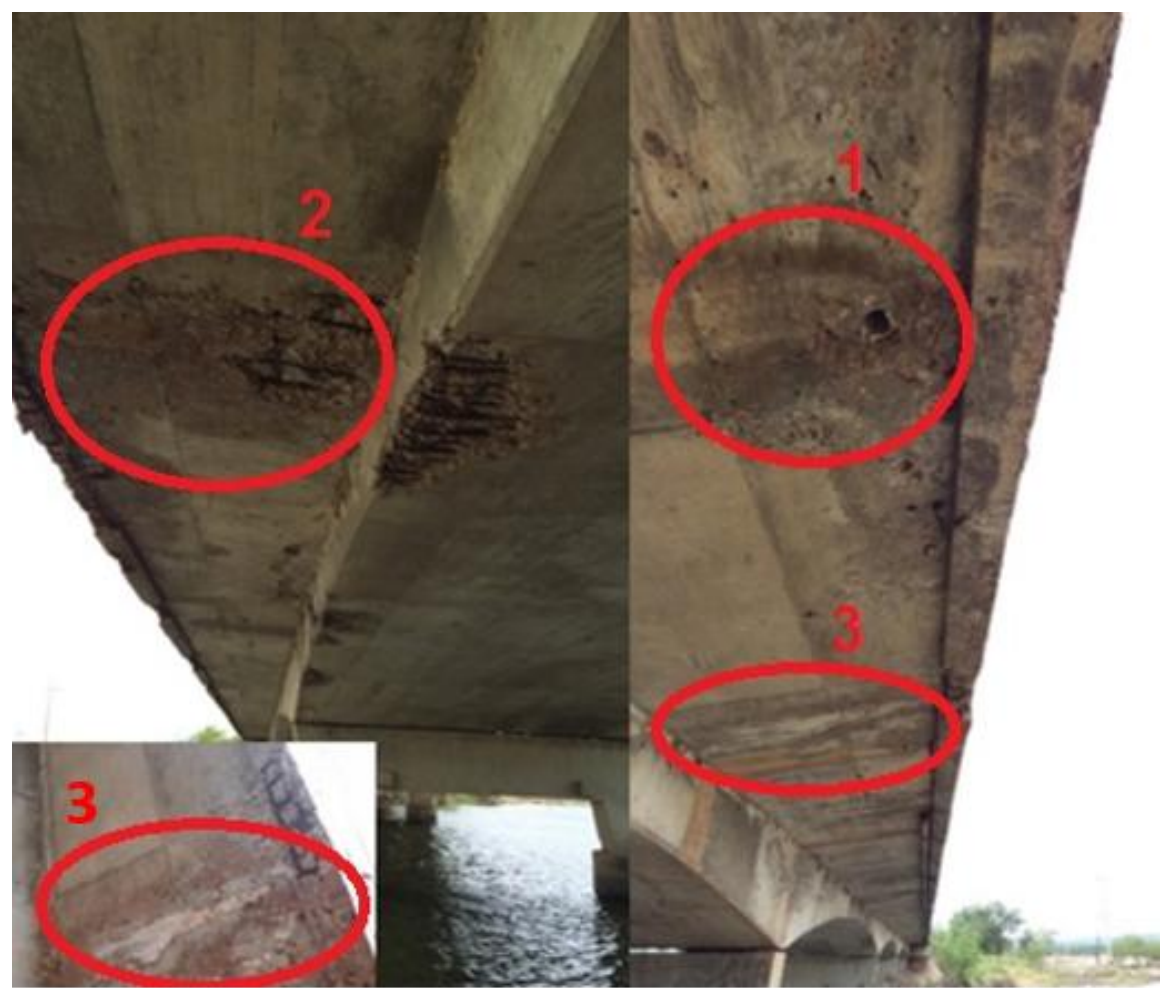

Figura 6 - Manifestações patológicas na mesoestrutura; (1) desplacamento e armaduras corroídas, (2) processo de fissuração, (3) consoles com cobrimento insuficiente e armaduras expostas e corroídas, (4) desgaste e esmagamento do neoprene
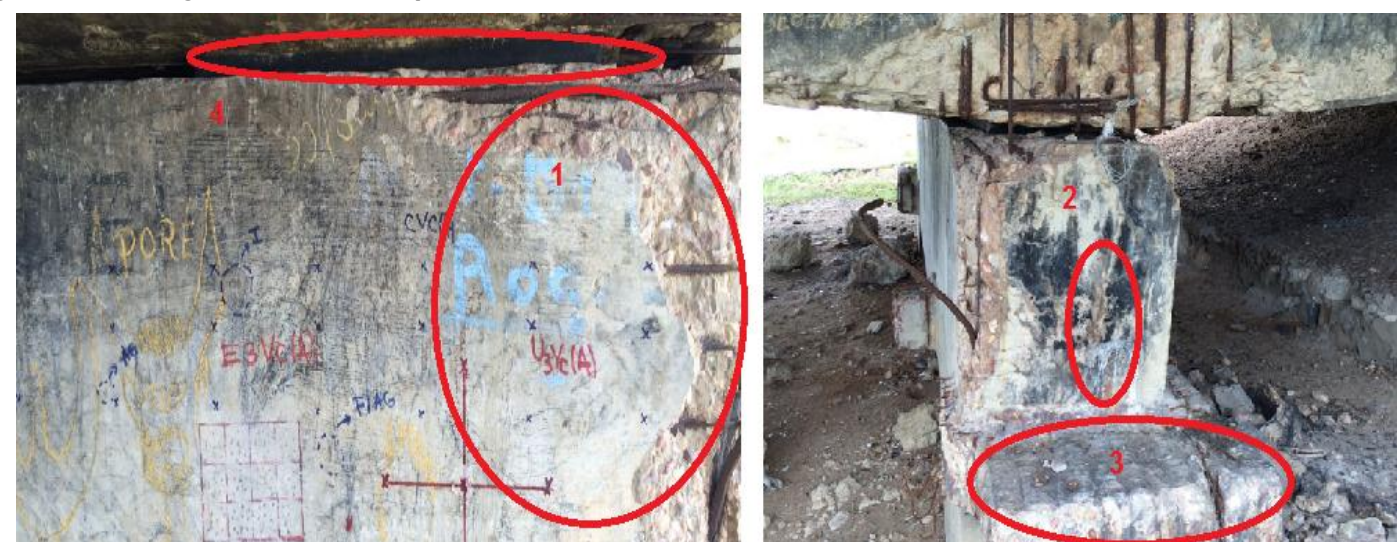
Figura 7 - Manifestações patológicas encontradas no primeiro vão interno da laje inferior; (1) perda de cobrimento e corrosão ativa das armaduras, (2) desplacamento do concreto

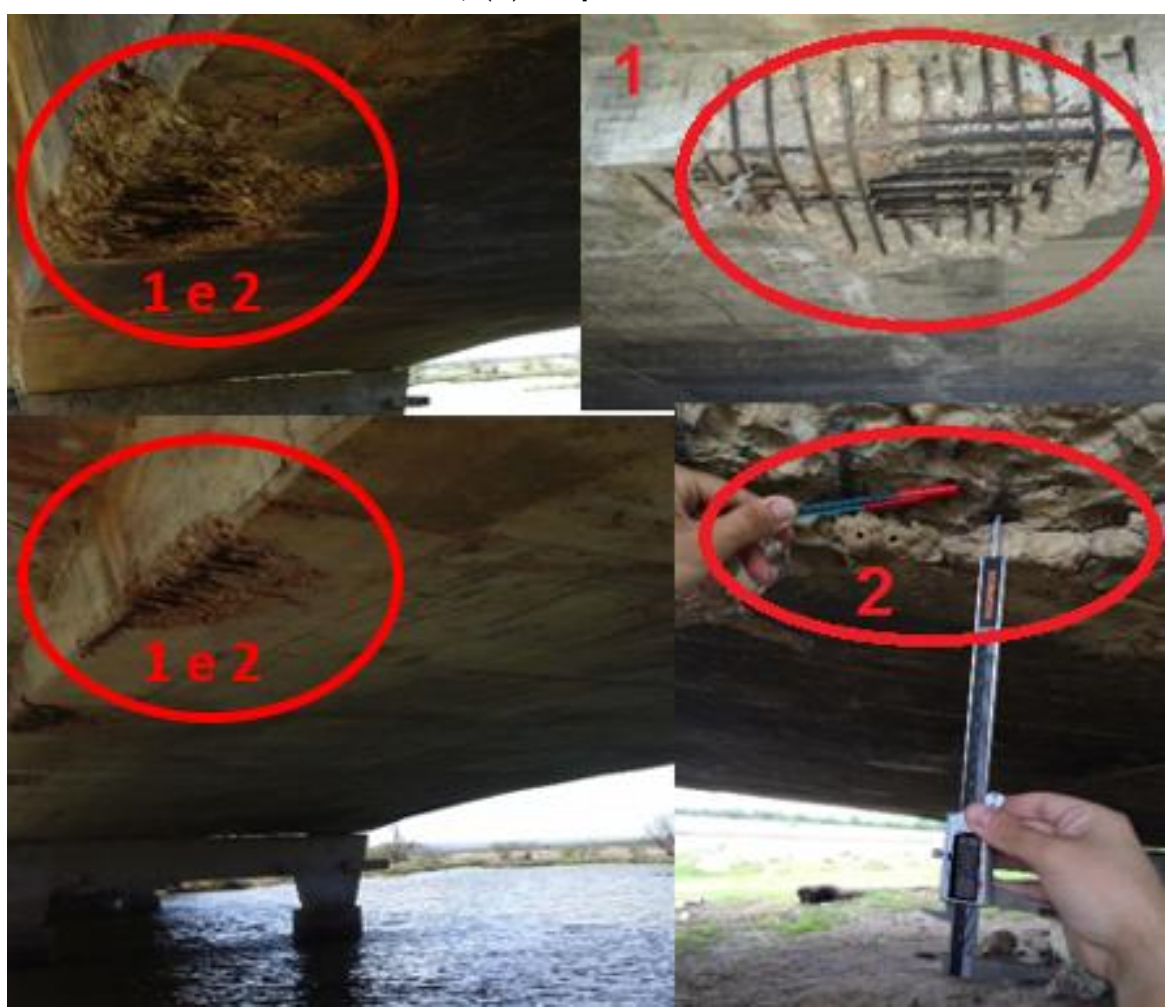

\section{Metodologia GDE adaptada para OAE}

A partir das manifestações patológicas encontradas nos elementos da ponte através das inspeções, foi possível construir as composições dos elementos para o cálculo de deterioração da estrutura, de acordo com a metodologia GDE adaptada para OAE.

A partir dessa combinação, foi possível obter valores numéricos que quantificam e classificam a estrutura de forma mais específica e global, através do arranjo de seus elementos em classes de famílias.

Para tanto, na análise dos resultados, é discutida a aplicação da metodologia em: grau do dano dos elementos, grau do dano das famílias, grau de deterioração global da estrutura (GDE).

A Figura 8 apresenta a classificação de deterioração dos elementos da superestrutura em nível "crítico" para as composições de acordo com Fonseca (2007) e Euqueres (2011), e "crítico" e "Sofrível", respectivamente, referente às composições que foram inseridas a partir das adaptações dos fatores de intensidade alterados. Dessa forma, verifica-se redução de $36,80 \%$ para os balanços da laje superior e de 39,83\% para as lajes inferiores dos vãos internos 1 e 2.

É possível observar que, mesmo com uma redução considerável, não se pôde diminuir o estado de deterioração dos balanços da laje superior para "Sofrível", porém houve uma na diminuição do GDE global da estrutura.

Para os demais elementos, foram obtidos níveis "altos" nas cortinas e "baixos" a "médios" para as demais lajes. Isso evidencia que, para quase todos esses elementos, não houve uma redução consideravelmente significativa em relação aos elementos analisados anteriormente, exceto a evidente redução encontrada nas lajes de transição, cerca de $74,40 \%$.

A composição das famílias dos elementos da ponte teve duas concepções: no arranjo dos elementos com o mesmo fator de relevância segundo Euqueres (2011), em 5 famílias (famílias FR); e na individualização de cada elemento da estrutura como sendo uma família. Com isso, compondo 10 famílias (famílias divididas). Esse critério foi apresentado na Tabela 2. 
Figura 8 - Grau do dano dos elementos da superestrutura

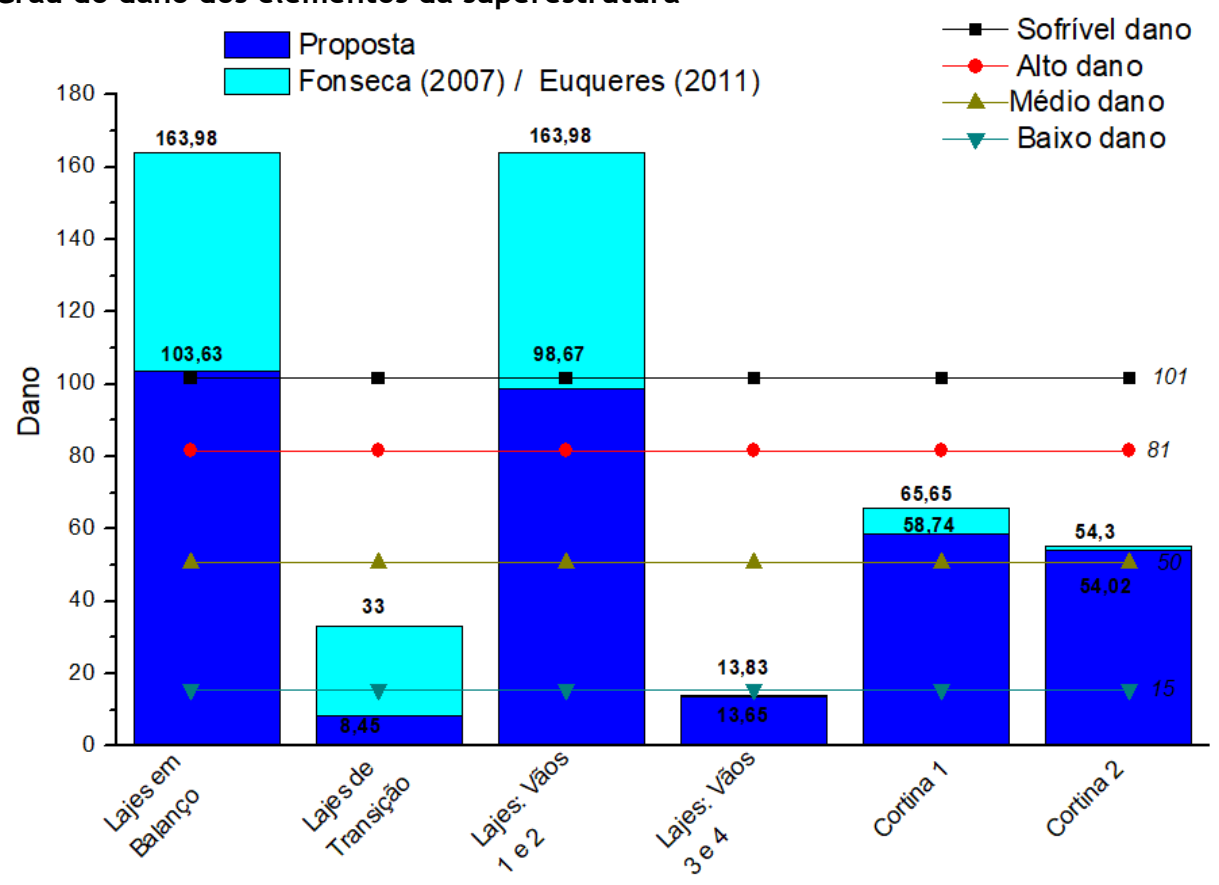

As Figuras 9 e 10 ilustram a quantificação das famílias dos elementos sobrepostos de acordo com os fatores ponderação e de intensidade das reformulações de Fonseca (2007) e Euqueres (2011), bem como utilizando adaptações propostas nos fatores de intensidade nesta pesquisa.

Da Figura 9 pode-se extrair que duas das cinco famílias apresentaram níveis de deterioração "sofrível”, as famílias FR1 e FR5. A família FR3 possuiu nível "alto", enquanto FR2 (composta por pista de rolagem) possuiu nível "baixo". A família FR4, que contém os balanços da laje superior, os vãos internos 1 e 2 e as vigas de acabamento, apresentou maior grau de deterioração em nível "crítico".

Com a aplicação dos fatores de intensidade adaptados, percebe-se que há redução significativa nas famílias da ordem de $7,10 \%$ a $62,80 \%$. Ressalta-se que essa diferença resultou em redução considerável no grau de deterioração global na composição dessas famílias de 127,67 a 88,53, qualificando uma redução de nível de deterioração da estrutura de crítico a sofrível.

Da Figura 9 pode-se observar a comprovação de que, diante dos danos apresentados em todos os elementos avaliados na composição das famílias, os balanços da laje superior, os vãos internos 1 e 2 e as vigas de acabamentos representam a porção mais deletéria da estrutura da ponte, juntamente com os aparelhos de apoio.

Os guarda-rodas, as vigas de contraventamento, as cortinas e os pilares apresentaram grau de deterioração "alto". Vale salientar que apenas os pilares, após a adaptação dos fatores de intensidade propostos na pesquisa, conseguiram reduzir o nível de deterioração para "médio". Esses aspectos observados revelaram que o estado de deterioração da maioria dos elementos foi considerado "alto", apresentando-se coerente com o estado global da estrutura. Os elementos que possuem danos inferiores a 15, como juntas de dilatação, pista de rolagem e a porção interna dos guarda-rodas, não entraram do cálculo do $G_{d}$, conforme a metodologia GDE original.

Em uma análise similar realizada na Figura 10, pode-se verificar redução global considerável na composição das famílias de acordo com os fatores de intensidade presentes nas reformulações de Fonseca (2007) e Euqueres (2011) com aqueles propostos nesta pesquisa. Isso resultou em redução do $G_{d}$ de 100,91 (nível crítico) para 64,03 (nível alto), evidenciando que a divisão em uma maior quantidade de famílias confere melhor refinamento da aplicação da metodologia, devido a uma maior ponderação.

A Figura 11 ilustra os resultados das metodologias utilizadas, obtidos a partir das variações das famílias FR/divididas com a aplicação dos fatores de ponderação das reformulações supracitadas e a proposta. Isso resultou em variações percentuais de $20,71 \%$ entre as famílias FR, utilizando o modelo por Fonseca (2007) e Euqueres (2011) sem alteração de nível de deterioração, ou seja, permanecendo em nível "crítico". 
Quanto às famílias divididas utilizando a reformulação dos fatores de ponderação propostos na Tabela 3, houve redução de $27,67 \%$ com alteração do nível de deterioração de status "Sofrível" para "alto", classificação a qual é compatível com o estado de conservação da ponte, mediante os danos presentes que, em princípio, não estão gerando problemas de perda de estabilidade ou mesmo comprometimento em serviço da OAE.

O grau de deterioração global da estrutura foi de 127,67 e 88,53 (famílias FR) e 100,91 e 64,03 (famílias divididas). Com isso, pode-se inferir que o valor numérico que mais se adequa às condições da ponte é de 64,03 , composto de todos os elementos inspecionados como sendo cada um deles uma família, juntamente com a aplicação dos fatores de intensidades propostos.

Dessa forma, sua classificação segundo a metodologia GDE adaptada para OAE refere-se a uma estrutura de nível de deterioração "alto", pois o $G_{d}$ está compreendido na faixa entre 50-81.

Figura 9 - Grau de deterioração das famílias FR

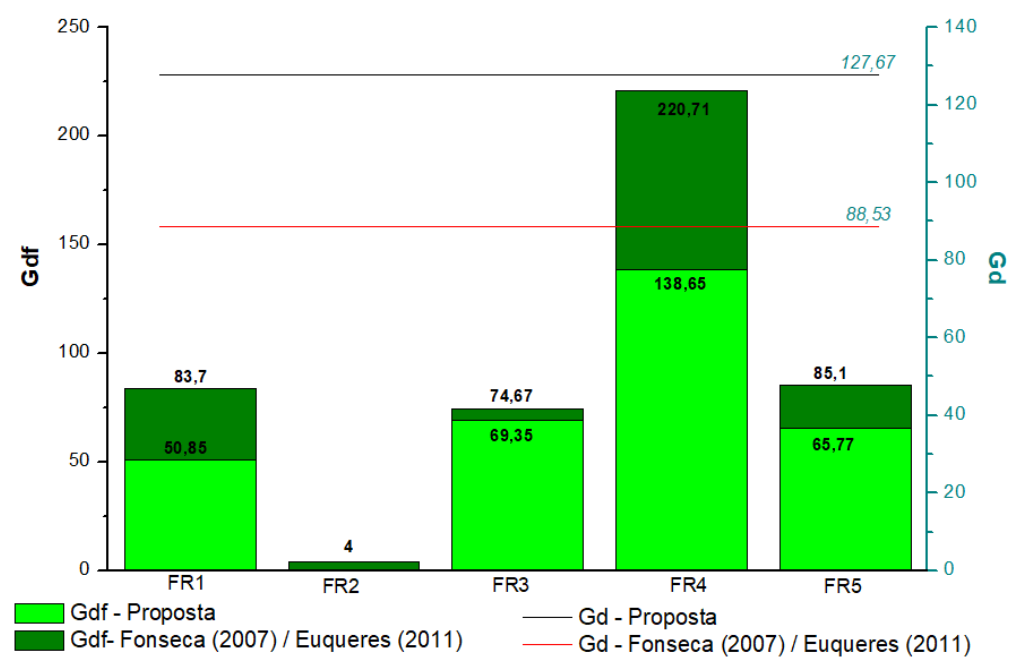

Figura 10 - Grau de deterioração das famílias divididas

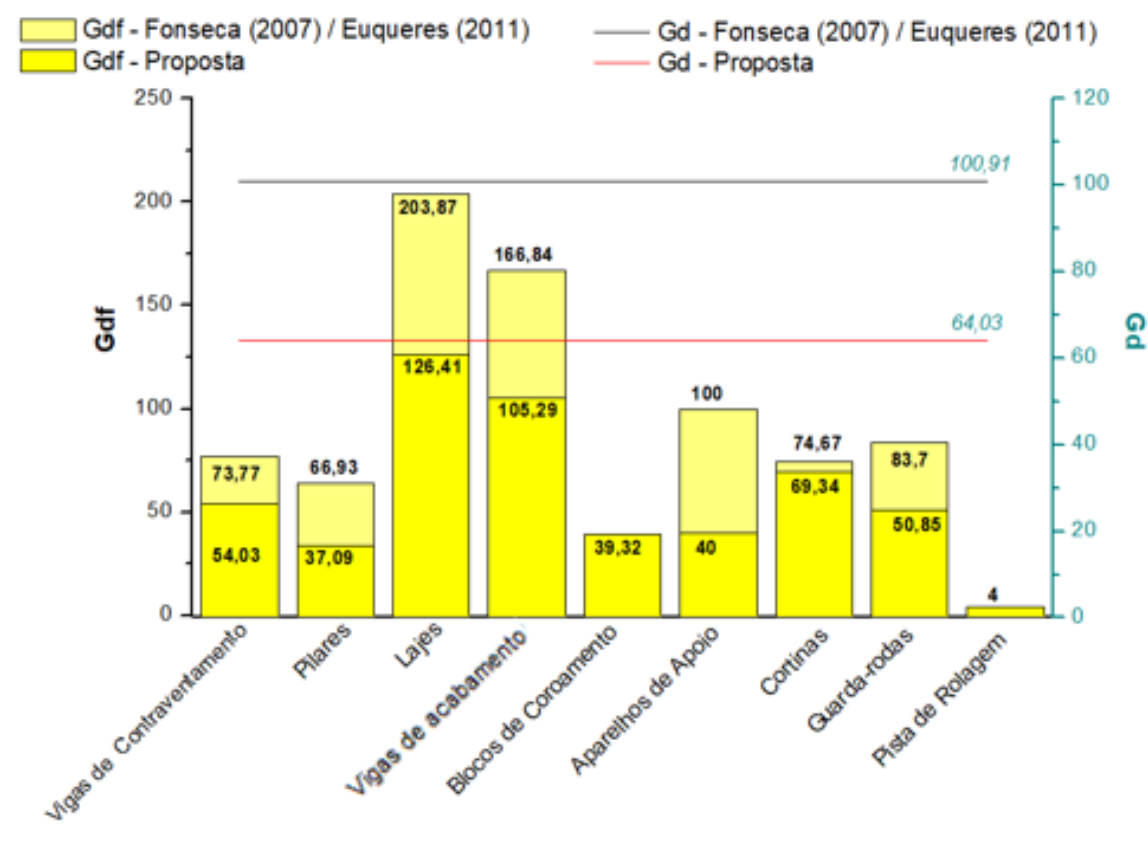


Figura 11 - Grau de deterioração global da estrutura

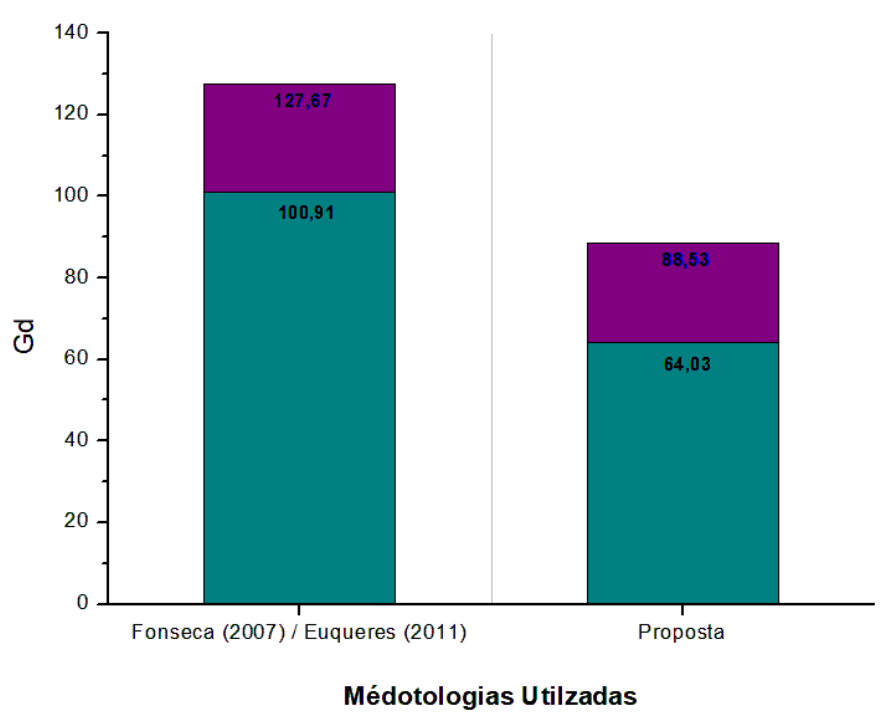

Diante disso, para realizar o processo de intervenção e recuperação da estrutura, devem ser aplicadas ações mediante a definição de prazo/natureza para inspeção especializada detalhada. De acordo as adaptações propostas por Euqueres (2011) deve-se planejar uma intervenção em curto prazo (no máximo 18 meses). Já segundo as modificações propostas nesta pesquisa, o prazo máximo proposto para a intervenção na ponte analisada será de 2 anos.

\section{Norma DNIT 010 (DEPARTAMENTO..., 2004)}

Para a utilização da metodologia proposta na norma DNIT 010 (DEPARTAMENTO..., 2004), foram aplicadas as fichas de inspeções e obtidas suas devidas avaliações interpretadas no Quadro 3. A Figura 12 ilustra o mapeamento de algumas manifestações patológicas incidentes na estrutura que corrobora tanto as análises da norma supracitada (Quadro 3), bem como o uso da metodologia GDE adaptada.

Do Quadro 3 verifica-se que, de forma geral, a partir dos elementos que a norma DNIT 010 (DEPARTAMENTO..., 2004) avalia, 50\% dos elementos válidos tiveram NTs iguais a 3, a qual as qualificam em estado "boa aparentemente", condições de estabilidade da obra diante das condições atuais. Quanto aos danos, as manifestações patológicas, com o tempo podem gerar alguma insuficiência estrutural, mas não há sinais de comprometimento quanto à estabilidade da obra.

Em relação aos demais 50\% dos elementos válidos, as avaliações indicaram NTs iguais a 4, classificando-os em "boas condições" de estabilidade. Da mesma forma, os danos inspecionados não indicam sinais de insuficiência estrutural.

Para as ações corretivas, os elementos que possuem NTs iguais a 3 indicam que a recuperação pode ser postergada, devendo-se, porém, colocar o problema em observação sistemática. Em relação aos elementos que possuem notas técnicas iguais a 4, a norma DNIT 010 (DEPARTAMENTO..., 2004) indica que não há nada a fazer, apenas serviços de manutenção.

Pode-se mencionar ainda, a partir de observação dos dados da Tabela 5, que os elementos referentes ao vigamento principal não tiveram avaliação. Tal fato se justifica por não haver longarinas como elemento estrutural constituinte da ponte.

Dessa forma, como prescreve a norma DNIT 010 (DEPARTAMENTO..., 2004), a NT final da ponte foi igual 3. Com isso, a ponte pode ser classificada quanto às condições de estabilidade como "boa aparentemente", embora ela seja enquadrada pela atribuição desta NT como uma obra "potencialmente problemática". Situação em que se recomenda acompanhar a evolução dos problemas através de inspeções rotineiras, a fim de detectar, em tempo hábil, um eventual agravamento de insuficiência estrutural. 


\section{Metodologia GDE adaptada para OAE versus norma DNIT 010 (DEPARTAMENTO..., 2004)}

A partir dos resultados referentes às metodologias de inspeção utilizadas aplicadas na ponte, pôde-se constatar que a forma de avaliar a estrutura segundo ambas as metodologias é distinta, pois, enquanto a norma DNIT 010 (DEPARTAMENTO..., 2004) possui um check-list pré-definido com os elementos a serem avaliados, a metodologia GDE adaptada para OAE possui maior flexibilidade na escolha dos elementos a serem inspecionados, bem como no agrupamento das famílias as quais irão compor o cálculo do $G_{d}$.

$\mathrm{Na}$ metodologia GDE adaptada para OAE há um maior número e especificidades de danos que podem ser catalogados, e a sua atribuição se dá por fatores de intensidade, embora sejam necessárias outras adaptações para estruturas de pontes, tendo em vista que esta metodologia inicialmente foi construída para aplicações em edificações.

Quanto ao procedimento da DNIT 010 (DEPARTAMENTO..., 2004), não existem valores que quantificam os danos e uma formulação final para calcular a deterioração da ponte, mas sim a atribuição de notas técnicas de acordo com a identificação dos danos presentes. Esse fato evidencia ainda mais a subjetividade na avaliação da OAE. Na metodologia GDE adaptada para OAE há formulações embasadas e fatores de ponderação aplicados às manifestações patológicas identificadas, que determinam um número de degradação global da estrutura. Esses fatores, pelo seu caráter qualitativo e quantitativo, auxiliam em uma minimização relativa da subjetividade do procedimento de inspeção ao avaliar o estado de deterioração de um OAE.

Figura 12 - Mapeamento das manifestações patológicas

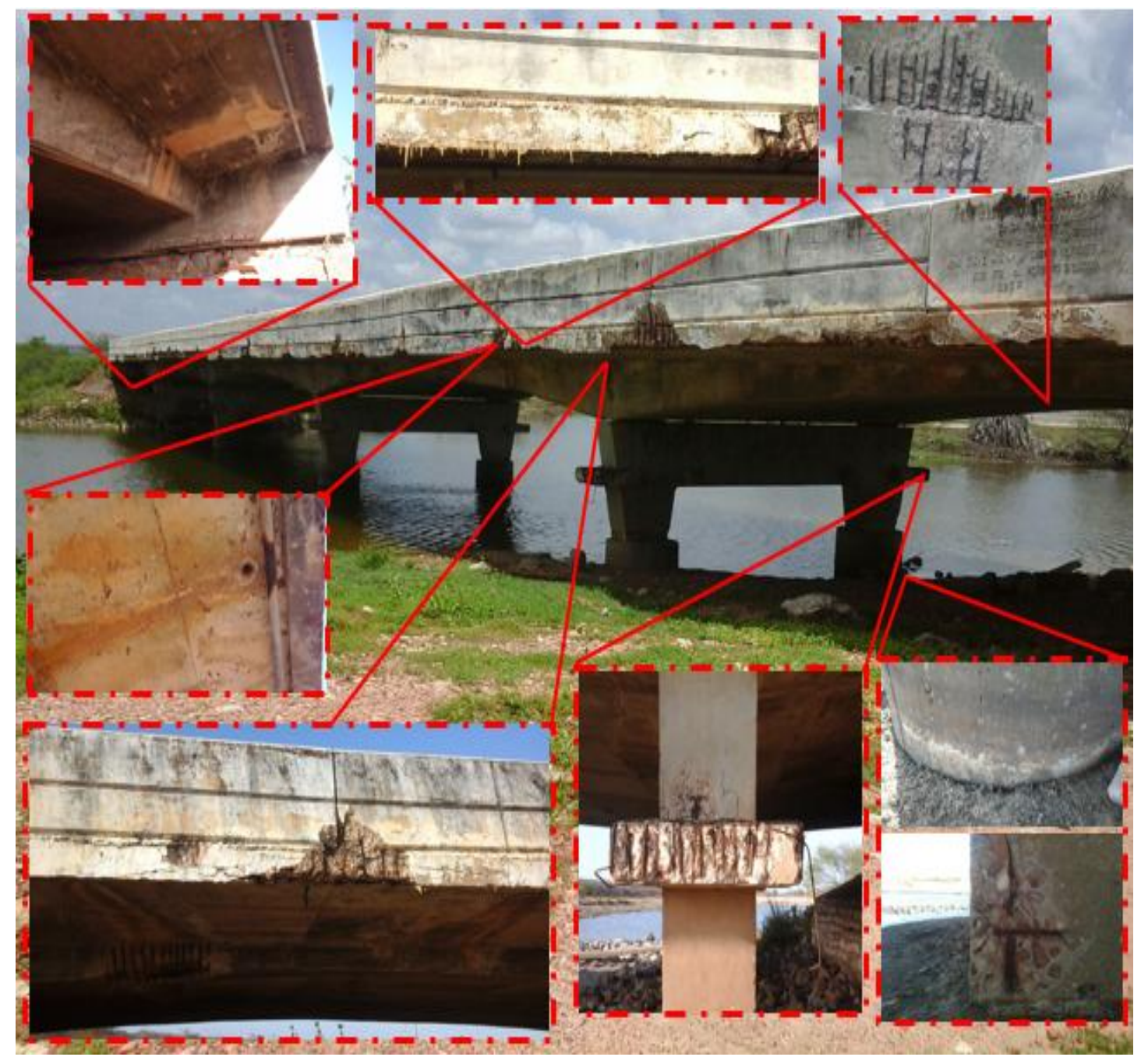


Quadro 3 - Aplicação da norma DNIT 010 (DEPARTAMENTO..., 2004)

\begin{tabular}{|c|c|}
\hline Elementos / NT & Manifestações patológicas \\
\hline $\begin{array}{c}\text { Lajes: } 3 \\
\text { (Boa aparentemente) }\end{array}$ & $\begin{array}{l}\text { - Existem regiões de desplacamentos de concreto ao longo dos vãos inferiores da laje; } \\
\text { - Em regiões onde há desplacamentos de concreto, as armaduras estão expostas e bastante } \\
\text { oxidadas (corrosão ativa) e perda de seção das barras, visíveis ao olho humano; } \\
\text { - Possui algumas regiões com grande incidência de manchas de umidade, oriundas de um } \\
\text { sistema drenagem danificando e ineficiente, sem direcionamento de fluxo; } \\
\text { - Possui a incidências de algumas fissuras; } \\
\text { - Concreto de baixa qualidade e, em algumas, áreas de baixa aderência ao aço devido ao } \\
\text { desplacamento; } \\
\text { - Cobrimento insuficiente em áreas consideráveis; } \\
\text { - Grande incidência de concreto desagregado. }\end{array}$ \\
\hline $\begin{array}{l}\text { Vigamento principal } \\
\text { (Sem avaliação) }\end{array}$ & $\begin{array}{l}\text { - Devido a estrutura da ponte ser dotada de seção por caixão celular, não é visível e nem se } \\
\text { pode afirmar se existe vigamento principal. }\end{array}$ \\
\hline $\begin{array}{c}\text { Mesoestrutura: } 3 \\
\text { (Boa aparentemente) }\end{array}$ & $\begin{array}{l}\text { - Em regiões onde há desplacamentos de concreto, as armaduras estão expostas e bastante } \\
\text { oxidadas (corrosão ativa) e perda de seção das barras, visíveis ao olho humano; } \\
\text { - Grande incidência de concreto desagregado; } \\
\text { - Possui incidências de algumas fissuras; } \\
\text { - Aparelho de apoio visivelmente desgastado; } \\
\text { - Concreto de baixa qualidade em pequenas áreas de baixa aderência ao aço devido ao } \\
\text { desplacamento; } \\
\text { - Cobrimento insuficiente em pequenas áreas; } \\
\text { - Sem desaprumo visível ou aparente; } \\
\text { - Sem deslocamento dos pilares visível ou aparente. }\end{array}$ \\
\hline $\begin{array}{l}\text { Infraestrutura: } 4 \\
\text { (Boa) }\end{array}$ & $\begin{array}{l}\text { - Sem recalque visível ou aparente; } \\
\text { - Sem deslocamento visível ou aparente; } \\
\text { - Média incidência da erosão do terreno da fundação; } \\
\text { - Não há estacas desenterradas, pois a fundação profunda é do tipo tubulão. }\end{array}$ \\
\hline $\begin{array}{l}\text { Pista/Acesso: } 4 \\
\text { (Boa) }\end{array}$ & $\begin{array}{l}\text { - Poucas irregularidades no pavimento da pista de rolagem; } \\
\text { - Juntas de dilatação com pequenas obstruções do material elástico devido a abrasão e com } \\
\text { baixíssimas incidências de umidade; } \\
\text { - Acesso versus ponte com degrau não acentuado e sem problemas de concordância. No } \\
\text { entanto, estrutura de guarda-rodas e guarda-corpo não adequados; } \\
\text { - Sem informações sobre relatos de acidentes frequentes com veículos. }\end{array}$ \\
\hline NT da ponte & $\begin{array}{c}3 \\
\text { (Boa aparentemente) }\end{array}$ \\
\hline
\end{tabular}

\section{Conclusões}

(a) as inspeções visuais realizadas in loco identificaram concreto desplacado e desagregado, manchas de eflorescência (até formações de estalactites), falhas de concretagem, exposição e corrosão das armaduras e fissuras. A maioria dessas manifestações foi localizada nas lajes inferiores dos vãos internos e em balanços da laje superior, bem como em alguns pilares da mesoestrutura da ponte;

(b) na aplicação da metodologia GDE adaptada para OAE, mediante as variações de cálculo propostas, classificou a ponte em nível "alto" de deterioração $\left(G_{d}=64,03\right)$, com recomendação de intervenção em curto prazo (máximo de 24 meses);

(c) na aplicação da norma DNIT 010 (DEPARTAMENTO..., 2004) as notas técnicas (NTs) variaram entre os elementos de 3 a 4, obtendo assim como nota global da ponte igual 3. Essa nota caracteriza a ponte com danos que geram alguma insuficiência estrutural, mas que não possui sinais de comprometimento da estabilidade da obra. Dessa forma, a ação corretiva baseada na recuperação da obra poderá ser postergada, devendo-se, porém, ser observada de forma sistemática, na minimização do agravamento de insuficiência estrutural;

(d) Quanto ao comparativo entre ambas as metodologias utilizadas, elas são condicionadas à qualificação do inspetor responsável. A metodologia GDE adaptada para OAE permite uma quantificação mais específica, devido à aplicação dos respectivos fatores de ponderação. Esses fatores subsidiam maior suporte ao inspetor responsável pela avaliação da OAE; e

(e) as reformulações propostas permitem reproduções deste estudo para outras pontes de concreto armado. 


\section{Referências}

ABOUHAMAD, M. et al. Corrosiveness mapping of bridge decks using image-based analysis of GPR data. Automation in Construction, v. 80, p. 104-117, 2017.

ALSHARQAWI, M.; ZAYED, T.; ABU DABOUS, S. Integrated condition rating na forecasting method for bridge decks using Visual Inspection and Ground Penetrating Radar. Automation in Construction, v. 89, p. 135-145, 2018.

ANN, K. Y. et al. Service life prediction of a concrete bridge structure subject to carbonation. Construction and Building Materials, v. 24, p. 1494-1501, 2010.

ARAÚJO, A.; PANOSSIAN, Z. Durabilidade de estruturas de concreto em ambiente marinho: estudo de caso. In: INTERCORR, 30., Fortaleza, 2010. Anais [...] Fortaleza, 2010.

ASSOCIAÇÃO BRASILEIRA DE NORMAS TÉCNICAS. NBR 6118: projeto de estruturas de concreto: procedimento. Rio de Janeiro, 2014.

BOLDO, P. Avaliação quantitativa de estruturas de concreto armado de edificações no âmbito do Exército Brasileiro. Brasília, 2002. 295 f. Dissertação (Mestrado em Engenharia Civil) -Escola de Engenharia, Universidade de Brasília, Brasília, 2002.

CAMPOS NETO, T. F. et al. Centro de planejamento da UnB: aspectos históricos, mapeamento dos níveis de deterioração na estrutura e propostas de intervenção. Ambiente Construído, Porto Alegre, v. 18, n. 3, p. 239-254, jul./set. 2018.

CASTRO, E. K. Desenvolvimento de metodologia para manutenção de estruturas de concreto armado. Brasília, 1994. 129 f. Dissertação (Mestrado em Engenharia Civil) - Escola de Engenharia, Universidade de Brasília, Brasília, 1994.

COSTA, A.; APPLETON, J. Case studiesof concrete deterioration in a marine environment in Portugal. Cementand Concrete Composites, v. 24, p. 169-179, 2002.

DEPARTAMENTO NACIONAL DE INFRAESTRUTURA DE TRANSPORTES. DNIT 010 - PRO: inspeções em pontes e viadutos de concreto armado e protendido: procedimento. Rio de Janeiro, 2004.

DEPARTAMENTO NACIONAL DE INFRAESTRUTURA DE TRANSPORTES. DNIT-Relatório gerencial |Atlas de manutenção rodoviária. Brasília, 2017b.

DEPARTAMENTO NACIONAL DE INFRAESTRUTURA DE TRANSPORTES. DNIT-Sistema Nacional de Viação. Coordenação-Geral de Operações. Brasília, 2017a.

EUQUERES, P. Metodologia de inspeção em estruturas de pontes de concreto armado. Goiânia, 2011. 168 p. Dissertação (Mestrado em Engenharia Civil) -Escola de Engenharia, Universidade Federal de Goiás, Goiânia, 2011.

FONSECA, R. P. A estrutura do Instituto Central de Ciências: aspectos históricos, científicos e tecnológicos de projeto, execução, intervenções e propostas de manutenção. Brasília, 2007. $213 \mathrm{f}$. Dissertação (Mestrado em Engenharia Civil) - Escola de Engenharia, Universidade de Brasília, Brasília, 2007.

GIOVANNETTI, A. C.; PINTO, R. C. A. Avaliação da condição de uma ponte: estudo de caso. In: CONGRESSO BRASILEIRO DE PONTES E ESTRUTURAS, 7., Rio de Janeiro, 2014. Anais [...] Rio de Janeiro, 2014.

GONÇALVES, M. O. Marquises de concreto armado da cidade de Viçosa - MG: manifestações patológicas, inspeção e avaliação de grau de deterioração. Viçosa, 2011. 183 f. Dissertação (Mestrado em Engenharia Civil) - Escola de Engenharia, Universidade Federal de Viçosa, Viçosa,2011.

KLEIN, D. et al. Critérios adotados na vistoria de obras de arte. In: JORNADAS SUL-AMERICANAS DE ENGENHARIA ESTRUTURAL, 25., Porto Alegre, 1991. Anais [...] Porto Alegre, 1991.

LOPES, B. A. R. Sistema de manutenção predial para grandes estoques de edifícios: estudo para inclusão do componente "Estrutura de Concreto". Brasília, 1998. 150 f. Dissertação (Mestrado em Engenharia Civil) - Escola de Engenharia, Universidade de Brasília, Brasília, 1998. 
MENDONÇA, J. A. F. et al. Avaliação da estrutura do estádio Manuel Leonardo Nogueira, em Mossoró/RN, por meio da metodologia GDE/UnB. In: CONGRESSO BRASILEIRO DO CONCRETO, 56., Natal, 2014.Anais [...] Natal, 2014.

PEREIRA, H. W. B. Identificação das condições gerais de conservação nos reservatórios integrantes do sistema de abastecimento de água de Natal. Natal, 2014. 154 f. Dissertação (Mestrado em Engenharia Civil) -Escola de Engenhariam Universidade Federal do Rio Grande do Norte, Natal, 2014.

PLANO NACIONAL DE LOGÍSTICA INTEGRADA. Empresa de Planejamento e Logística. Brasília, 2016.

ROSA, F. B. et al. Comparação das metodologias de inspeção em obras de arte: metodologia GDE/UnB e DNIT. In: CONGRESSO BRASILEIRO DO CONCRETO, 56., Natal, 2014. Anais [...] Natal, 2014.

ZHOU, M. et al. Applicationof ultra-high performance concrete in bridge engineering. Construction and Building Materials, v. 186, p. 1256-1267, 2018.

\title{
Agradecimentos
}

Ao DNIT, pela concessão legal para se desenvolverem os estudos necessários na ponte sobre o Rio do Carmo, os quais foram propostos nesta pesquisa. À Capes, pelo o apoio financeiro. Aos pesquisadores envolvidos.

Alisson Gadelha de Medeiros

Departamento de Engenharias e Tecnologia | Universidade Federal Rural do Semi-Árido | Rodovia BR-226, km 405 | Pau dos Ferros - RN Brasil | CEP 59900-000 | E-mail: alisson.gadelha@ufersa.edu.br

Maria das Vitórias Vieira Almeida de Sá

Programa de Pós-Graduação em Engenharia Civil, Departamento de Engenharia Civil | Universidade Federal do Rio Grande do Norte | Rua das Engenharias, s/n | Natal - RN - Brasil | CEP 59078-900 | E-mail: vitoria@ct.ufrn.br

José Neres da Silva Filho

Programa de Pós-Graduação em Engenharia Civil, Departamento de Engenharia Civil । Universidade Federal do Rio Grande do Norte | Email: jneres@ect.ufrn.br

\section{Marcos Alyssandro Soares dos Anjos}

Instituto Federal de Educação, Ciência e Tecnologia da Paraíba | Programa de Pós-graduação em Engenharia Civil | Universidade Federal do Rio Grande do Norte | Av. Primeiro de Maio, 720 | João Pessoa - PB - Brasil | CEP 58015-435 | E-mail: marcos.anjos@ifpb.edu.br

\author{
Ambiente Construído \\ Revista da Associação Nacional de Tecnologia do Ambiente Construído \\ Av. Osvaldo Aranha, $99-3^{\circ}$ andar, Centro \\ Porto Alegre - RS - Brasil$$
\text { CEP } 90035-190
$$ \\ Telefone: +55 (51) 3308-4084 \\ Fax: +55 (51) 3308-4054 \\ www.seer.ufrgs.br/ambienteconstruido \\ E-mail: ambienteconstruido@ufrgs.br
}

